\title{
Investigation of transformer failure in Indonesia
}

\author{
Brian Bramantyo S.D.A. Harsono ${ }^{1},{ }^{*}$, Aristo Adi Kusuma ${ }^{1}$, Buyung Sofiarto Munir ${ }^{1}$ and Nur Widi Priambodo ${ }^{1}$ \\ ${ }^{1}$ PLN Research Institute, Transmission and Distribution Department, Jakarta
}

\begin{abstract}
Transformer failure investigation is important to obtain necessary actions which prevent similar failure from happening in the future. An investigation was conducted upon the failure of a transformer in Indonesia which damaged substation apparatuses nearby. To determine possible cause of the failure, the investigation was performed by doing visual inspection after failure, further analysis on related historical assessment result data and simulation using related nameplate and actual configuration. Most historical assessment result data showed no early failure indication of the transformer, while sweep frequency response analysis (SFRA) test result showed severe deformation on both primary and secondary winding. A simulation using Transient Analysis Program for internal short circuit between winding and ground was conducted and the output waveform was identical to Digital Fault Recorder (DFR) waveform data during transformer failure. Therefore, the possible cause of transformer failure was internal arcing on primary winding to ground which could not be interrupted by the protection system. According to visual inspection after failure, the possible cause of protection system malfunction was accidental open circuit in Current Transformer (CT) secondary circuit which damaged whole CT wiring.
\end{abstract}

\section{Introduction}

In power system, transformer holds important role to maintain power delivery and voltage stability across transmission network. Routine assessment data analysis and evaluation on previously recorded fault are necessary to monitor the condition of the transformer and to take required action to maintain performance and reliability of the transformer itself. Further analysis can be performed toward routine maintenance test such as tan delta, Polarization Index (PI), Dissolved Gasses Analysis (DGA) etc. [1]. Along with routine assessment data, Sweep Frequency Response Analysis (SFRA) has provided valuable information regarding transformer's internal characteristic such as core, windings or termination [2-7].

In 2017, a transformer in Indonesia experienced sudden failure resulting collateral damage to another apparatus which were electronically connected to the transformer, such as transformer bay marshalling kiosk, high voltage arrester on the secondary side of the transformer, $150 \mathrm{kV}$ Current Transformer (CT) on the primary side of the transformer and also relay panel on control room. Field data evaluation and related simulation was conducted to investigate the possible cause of the failure.

\section{Methodology}

The collected field data consist of visual inspection after failure, historical transformer assessment data and Digital Fault Recorder (DFR) data. Historical transformer assessment data was analyzed using related standard, while visual inspection and DFR data were analyzed to generate related fault model in Electromagnetic Transient Program which could represent the possible cause of the transformer failure. The transformer parameters used in simulation was adjusted and configured accordingly according to transformer nameplate and actual configuration in order to provide reliable result. The result of the simulation was analyzed and compared with DFR data to determine the possible cause of the failure.

\section{Field data evaluation}

\subsection{Visual inspection of damaged apparatus}

As explained in introduction, several apparatus was severely damaged during the fault. Therefore, individual visual inspection was performed to obtain valuable information needed for the analysis. The specification of the transformer according to the nameplate was shown in Table 1. The neutral side of the transformer was connected to $29 \Omega$ Neutral Grounding Resistor (NGR). During visual inspection on the transformer, it was found that both primary and secondary bushing were shattered (Fig. 1). Visible white smoke was spotted flowing out from bushing turret which indicated the presence of hot spot inside the tank. For safety reason, further visual inspection such as climb up inspection was cancelled. As shown in Fig. 1, transformer tank was deformed which indicated the increase of internal pressure.

\footnotetext{
*Corresponding author: brian.adiputro@pln.co.id
} 
Table 1. Specification of the transformer.

\begin{tabular}{|c|c|c|c|c|}
\hline Transformer type & \multicolumn{4}{|c|}{ SFZ-100000/140 } \\
\hline Serial number & \multicolumn{4}{|c|}{ A 95011} \\
\hline Manufactured & \multicolumn{4}{|c|}{1995} \\
\hline Nominal Rating [MVA] & \multicolumn{4}{|c|}{$60 / 100$} \\
\hline Cooling system & \multicolumn{4}{|c|}{ ONAN/ONAF } \\
\hline Ambient temperature max & \multicolumn{4}{|c|}{40} \\
\hline Frequency [Hz] & \multicolumn{4}{|c|}{50} \\
\hline Phase & \multicolumn{4}{|c|}{3} \\
\hline Temperature rise oil & \multicolumn{4}{|c|}{53} \\
\hline Winding temperature rise & \multicolumn{4}{|c|}{58} \\
\hline Vector group & \multicolumn{4}{|c|}{ YNyno(d) } \\
\hline Impedance voltage [\%] & \multicolumn{4}{|c|}{10} \\
\hline Terminal & $\begin{array}{l}\text { Power } \\
\text { [MVA] }\end{array}$ & Voltgae [kV] & Current $[A]$ & BIL \\
\hline $\mathrm{U}, \mathrm{V}, \mathrm{W}$ & $60 / 100$ & 140 & $247.43 / 412.39$ & 650 \\
\hline $\mathrm{u}, \mathrm{v}, \mathrm{w}, \mathrm{O}$ & $60 / 100$ & 70 & $495 / 824.8$ & 325 \\
\hline 0 & & 15 & & \\
\hline NT & & 10 & & \\
\hline
\end{tabular}

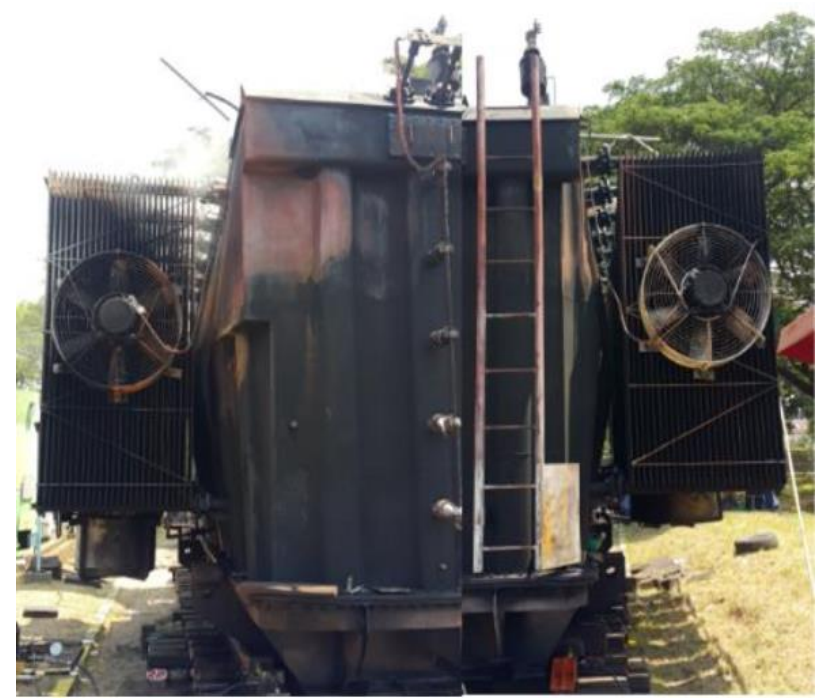

Fig. 1. Transformer condition after failure.

Marshalling kiosk of the transformer bay had burning mark on terminal $1-100$. The most severe damage could be seen on terminal 82 as shown in Fig. 2. According to the wiring diagram, terminal 82 was connected to $150 \mathrm{kV} \mathrm{CT}$ on the primary side of the transformer.

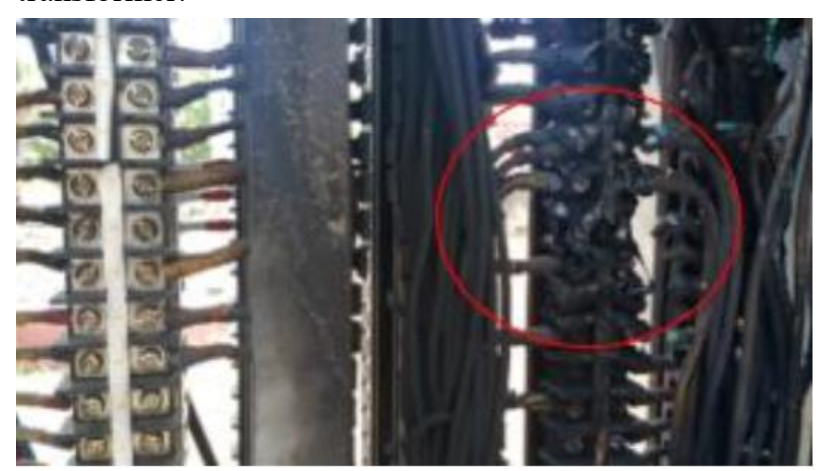

Fig. 2. Transformer condition after failure.

Further visual inspection on $150 \mathrm{kV}$ CT on the primary side of transformer revealed arcing mark on CT's core terminal cover (Fig. 3). All of the core terminal was burnt and some of them were melted as shown in Fig. 3.

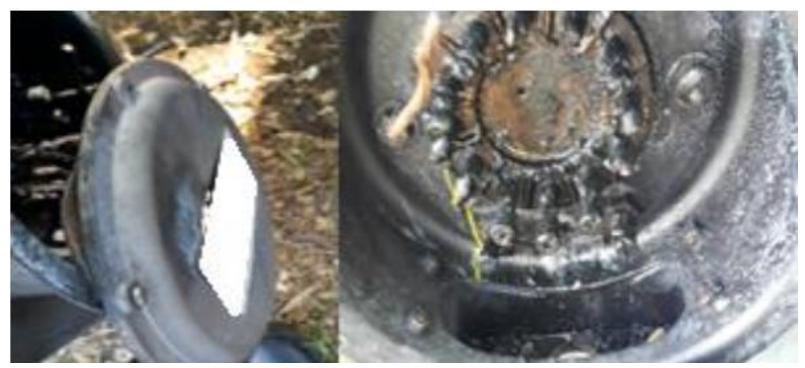

Fig. 3. $150 \mathrm{kV}$ CT terminal cover and core terminal condition.

High voltage lightning arrester on secondary side of the transformer had several-ruptured sheath and damaged counter as shown in Fig. 4.

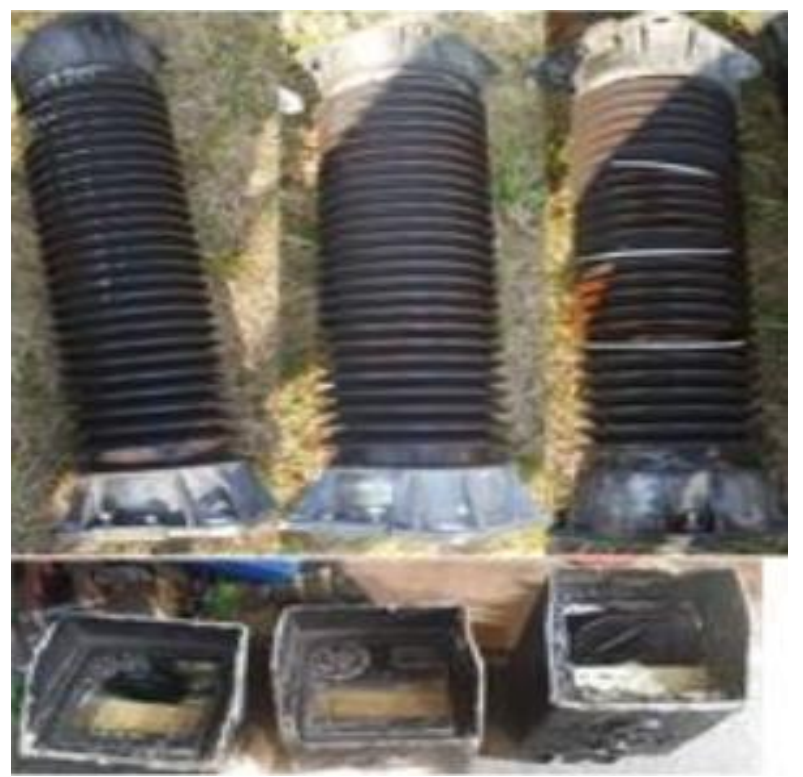

Fig. 4. Arresters on secondary and primary side of the transformer condition.

Visual inspection on relay panel of transformer bay showed arcing mark on the wall side (Fig. 5). Further investigation revealed that the arcing mark on the wall side was located next to $150 \mathrm{kV}$ CT module rack.

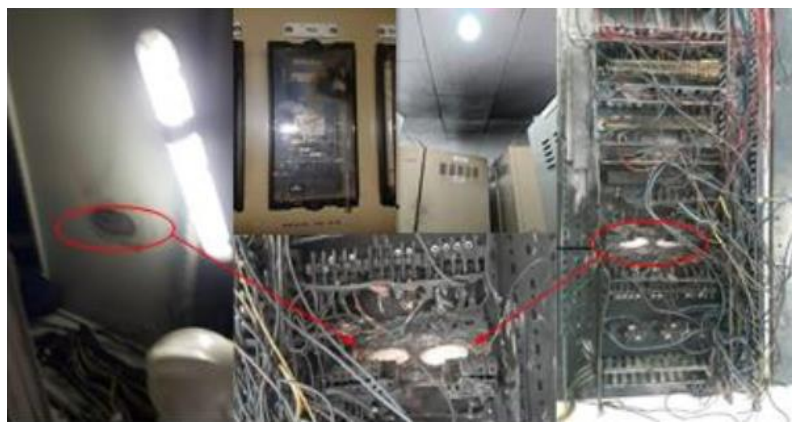

Fig. 5. Transformer bay relay panel condition.

\subsection{Visual inspection of damaged apparatus}

Historical transformer assessment data used in the evaluation were insulation resistance test result, tan delta test result and SFRA test result. Both insulation 
resistance test and tan delta test were performed in 2015 and 2017, while SFRA test was performed in 2015. The result of insulation resistance test was shown in Table 2. The polarization index of all test mode still above standard range 1.11-1.3 [1], hence the insulation of the transformer before failure was still in good condition. Note that the insulation between primary and earth and also between primary and tertiary had the lowest PI value, 1.44 .

Table 2. Insulation resistance test result.

\begin{tabular}{|l|c|c|c|c|c|c|}
\hline Reference & \multicolumn{2}{|c|}{2015} & \multicolumn{3}{c|}{2017} \\
\hline & 1 minute & 10 Minutes & $\mathrm{PI}$ & 1 minute & 10 Minutes & $\mathrm{PI}$ \\
\hline Primary - Earth & $3.22 \mathrm{G} \Omega$ & $4.46 \mathrm{G} \Omega$ & 1.38 & $2.72 \mathrm{G} \Omega$ & $3.94 \mathrm{G} \Omega$ & 1.44 \\
\hline Secondary - Earth & $2.77 \mathrm{G} \Omega$ & $4.8 \mathrm{G} \Omega$ & 1.73 & $2.96 \mathrm{G} \Omega$ & $4.03 \mathrm{G} \Omega$ & 1.57 \\
\hline Tertiary - Earth & $1.06 \mathrm{G} \Omega$ & $2.46 \mathrm{G} \Omega$ & 2.32 & $1.36 \mathrm{G} \Omega$ & $3.55 \mathrm{G} \Omega$ & 2.61 \\
\hline Primary - Secondary & $2.77 \mathrm{G} \Omega$ & $4.1 \mathrm{G} \Omega$ & 1.48 & $1.85 \mathrm{G} \Omega$ & $3.08 \mathrm{G} \Omega$ & 1.66 \\
\hline Primary - Tertiary & $3.35 \mathrm{G} \Omega$ & $5.07 \mathrm{G} \Omega$ & 1.51 & $3.09 \mathrm{G} \Omega$ & $4.47 \mathrm{G} \Omega$ & 1.44 \\
\hline Secondary - Tertiary & $1.81 \mathrm{G} \Omega$ & $3.07 \mathrm{G} \Omega$ & 1.47 & $1.75 \mathrm{G} \Omega$ & $2.74 \mathrm{G} \Omega$ & 1.56 \\
\hline
\end{tabular}

The result of transformer tan delta test was shown in Table 3. According to the reference, the maximum value of power dissipation is $0.5 \%$ [1]. Noted that almost all the tan delta value of transformer bellows $0.5 \%$, hence the transformer winding insulation before failure was in good condition.

Table 3. Transformer Tan Delta test result.

\begin{tabular}{|c|c|c|c|c|c|}
\hline \multirow{2}{*}{ Winding } & \multirow{2}{*}{ Mode } & \multicolumn{2}{|c|}{2015} & \multicolumn{2}{c|}{2017} \\
\cline { 3 - 6 } & & $\operatorname{Tan} \delta[\%]$ & Cap [nF] & Tan $\delta$ [\%] & Cap [nF] \\
\hline \multirow{4}{*}{ Primary } & UST-R & 0.09 & 7895.53 & 0.082 & 7928.67 \\
\cline { 2 - 6 } & UST-B & 0.144 & 351.5 & N/A & N/A \\
\cline { 2 - 6 } & GND-RB & 0.122 & 11788.5 & 0.095 & 11786.1 \\
\cline { 2 - 6 } & GAR-RB & 0.149 & 3505.63 & 0.117 & 3580.9 \\
\hline \multirow{4}{*}{ Secondary } & UST-R & 0.158 & 16594.5 & 0.135 & 16612.3 \\
\cline { 2 - 6 } & GND-RB & 0.144 & 26625.7 & 0.123 & 26713.05 \\
\cline { 2 - 6 } & GAR-RB & 0.201 & 2108.13 & 0.193 & 2173.96 \\
\hline \multirow{3}{*}{ Tertiary } & UST-R & 0.134 & 351.15 & 0.097 & 267.81 \\
\cline { 2 - 6 } & GND-RB & 0.218 & 30829.55 & 0.148 & 34024.4 \\
\cline { 2 - 6 } & GAR-RB & 0.28 & 13826.15 & 0.162 & 17142.2 \\
\hline
\end{tabular}

The result of transformer bushing tan delta test was shown in Table 4. According to the reference, the maximum value of power dissipation is $0.5 \%$ [1]. Noted that almost all the tan delta value of transformer bellows $0.5 \%$, hence the transformer bushing insulation before failure was in good condition.

Table 4. Bushing Tan Delta test result.

\begin{tabular}{|c|c|c|c|c|c|c|}
\hline \multirow{2}{*}{ Bushing } & \multirow{2}{*}{ Mode } & \multirow{2}{*}{ Note } & \multicolumn{2}{|c|}{2015} & \multicolumn{2}{|c|}{2017} \\
\hline & & & $\operatorname{Tan} \delta[\%]$ & $\operatorname{Cap}[\mathrm{nF}]$ & $\operatorname{Tan} \delta[\%]$ & $\operatorname{Cap}[\mathrm{nF}]$ \\
\hline \multirow{3}{*}{ Primary } & UST-R & Phase $R\left(C_{1}\right)$ & 0.232 & 249.59 & 0.242 & 249.65 \\
\hline & UST-B & Phase $5\left(C_{1}\right)$ & 0.256 & 245.37 & 0.273 & 246,11 \\
\hline & UST-R & Phase $T\left(C_{1}\right)$ & 0.228 & 247.93 & 0.28 & 247.89 \\
\hline \multirow{4}{*}{ Secondary } & UST-B & Phase R ( $\left.C_{1}\right)$ & 0.366 & 270.26 & 0.287 & 274.96 \\
\hline & UST-R & Phase $5\left(C_{1}\right)$ & 0.351 & 270.2 & 0.271 & 272.14 \\
\hline & UST-B & Phase $T\left(C_{1}\right)$ & 0.409 & 275.98 & 0.26 & 278.73 \\
\hline & UST-R & Phase $N\left(C_{1}\right)$ & 0.362 & 274.47 & 0.298 & 277.41 \\
\hline
\end{tabular}

SFRA test result showed severe deformation of primary and secondary winding as shown in Fig. 6 and Fig. 7. According to the reference, the frequency region for interaction between winding ranges between $2 \mathrm{kHz}$ and $20 \mathrm{kHz}$ while the frequency region for winding structure ranges between $20 \mathrm{kHz}$ and $1 \mathrm{MHz}$ [5]. For both region, the SFRA result for each phase was different one to another on primary and secondary winding.

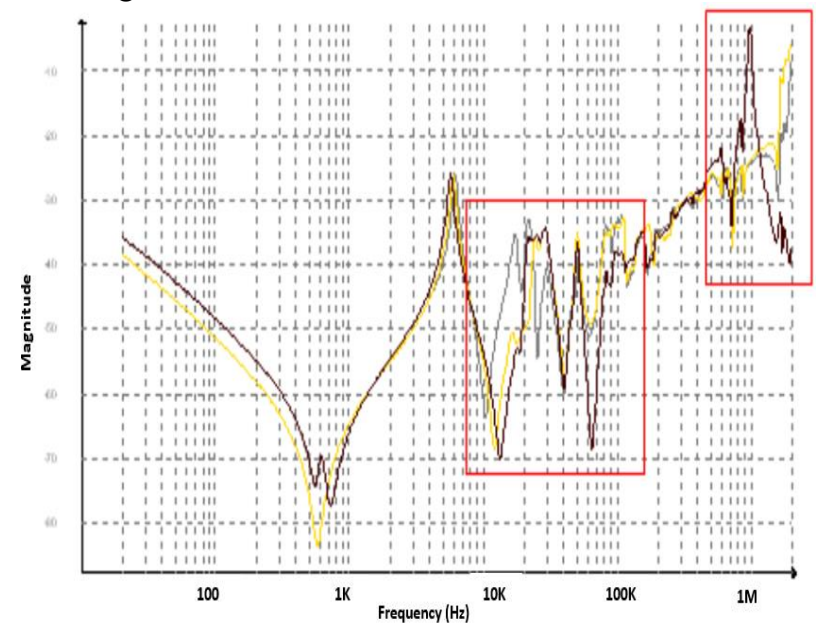

Fig. 6. SFRA result for primary winding (Phase $\mathrm{R}=$ grey, phase $\mathrm{S}=$ yellow and phase $\mathrm{T}=$ brown).

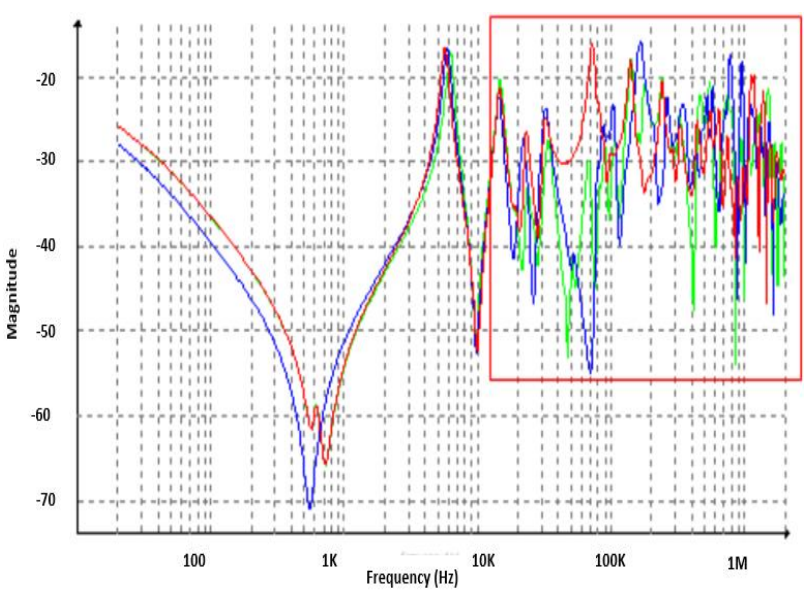

Fig. 7. SFRA result for secondary winding (Phase $r=$ green, phase $\mathrm{s}=$ blue and phase $\mathrm{t}=\mathrm{red}$ ).

Severe deformation on winding structure might indicate any clearance change or shift between primary and secondary winding and also between each winding toward transformer tank. This clearance shift affected the insulation strength resulting in possible insulation breakdown bellow the proposed design.

\subsection{Historical fault data of the transformer}

Previous fault on the transformer and the transmission line connected to the transformer could generate fault current which gave mechanical stress toward transformer winding [7-9]. Based on the fault data in 6 transmission line and the substation itself from 2016-2017, there were 11 faults which mostly consist of transmission line fault 
with distance relay attenuation. Those faults might contribute insulation degradation of the transformer.

\subsection{Digital fault recorder data}

The voltage and current waveform on the primary side of the transformer during the fault were shown in Fig. 8 and Fig. 9.

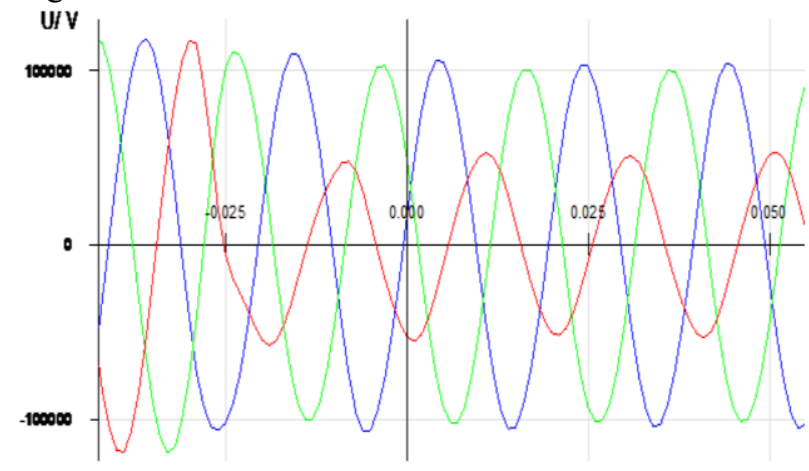

Fig. 8. Voltage waveform record during fault (Phase $\mathrm{R}=$ red, phase $\mathrm{S}=$ green and phase $\mathrm{T}=$ blue).

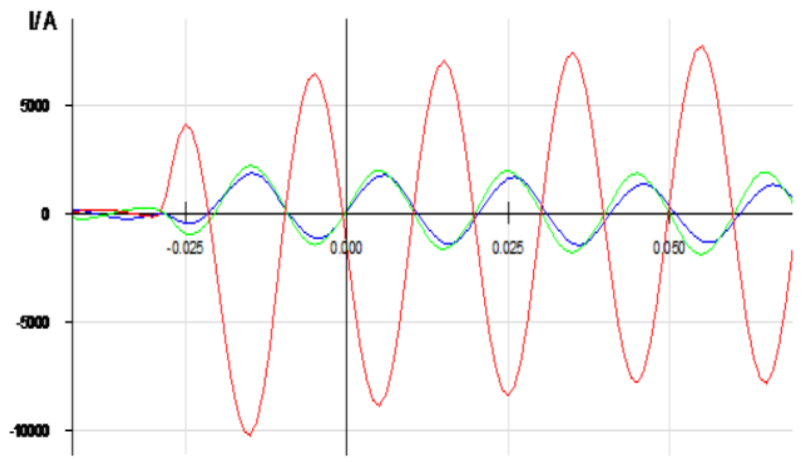

Fig. 9. Current waveform record during fault (Phase $\mathrm{R}=$ red, phase $\mathrm{S}=$ green and phase $\mathrm{T}=$ blue).

\section{Modelling and simulation}

Based on SFRA test result, the deformation on both primary and secondary windings were detected. The deformation could indicate winding position shift which might lead to possible short circuit from transformer winding to ground due to higher insulation stress. The possibility of phase to ground fault was supported with the DFR waveform pattern where the voltage of one phase was declining (phase R) and all the current waveform had the same phase angle. Deformed tank also served as an evidence of sudden pressure increase inside the transformer tank which might be caused by internal arcing. Simulation model for internal phase to ground fault on either primary winding or secondary winding was generated using Electromagnetic Transient Program as shown in Fig. 10. Note that the simulation used two $150 \mathrm{kV}$ transmission lines to represent the actual configuration of the substation.

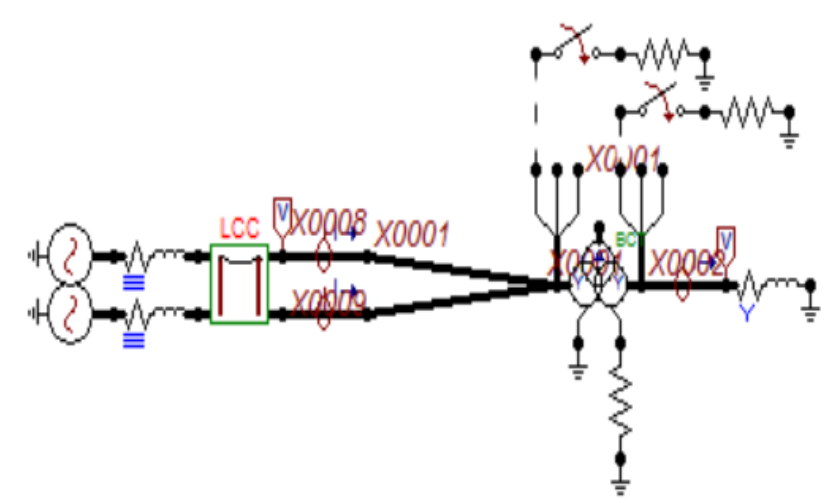

Fig. 10. Simulation model for phase to ground fault on transformer winding.

The voltage and current waveform for phase to ground fault simulation on primary winding (phase R) was shown in Fig. 11 and Fig. 12, while the voltage and current waveform for phase to ground fault simulation on low voltage winding (phase R) was shown in Fig. 13 and Fig 14. Based on the simulation result, ground fault on primary winding gave identical voltage and current waveform with the recorded waveform data of DFR.

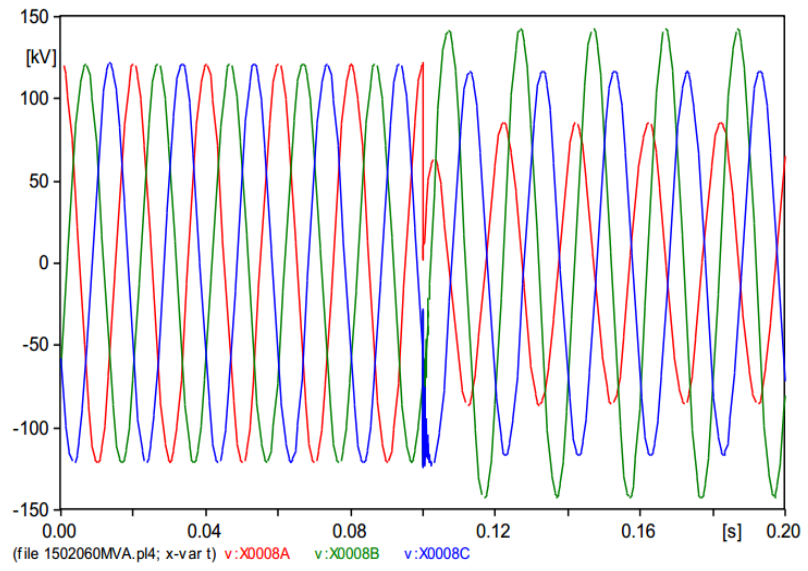

Fig. 11. Voltage waveform for phase to ground fault on primary winding ( $\mathrm{Phase} \mathrm{R}=$ red, phase $\mathrm{S}=$ green and phase $\mathrm{T}=$ blue).

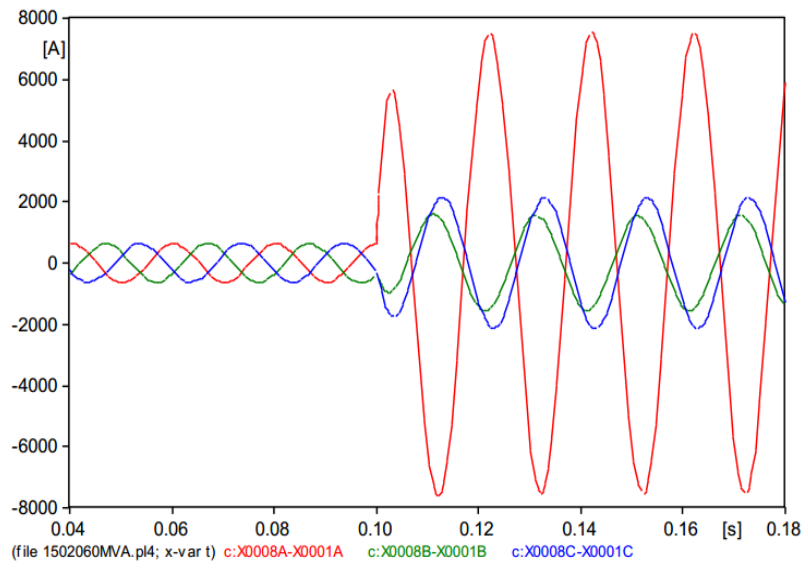

Fig. 12. Current waveform for phase to ground fault on primary winding (Phase $\mathrm{R}=$ red, phase $\mathrm{S}=$ green and phase $\mathrm{T}=$ blue). 


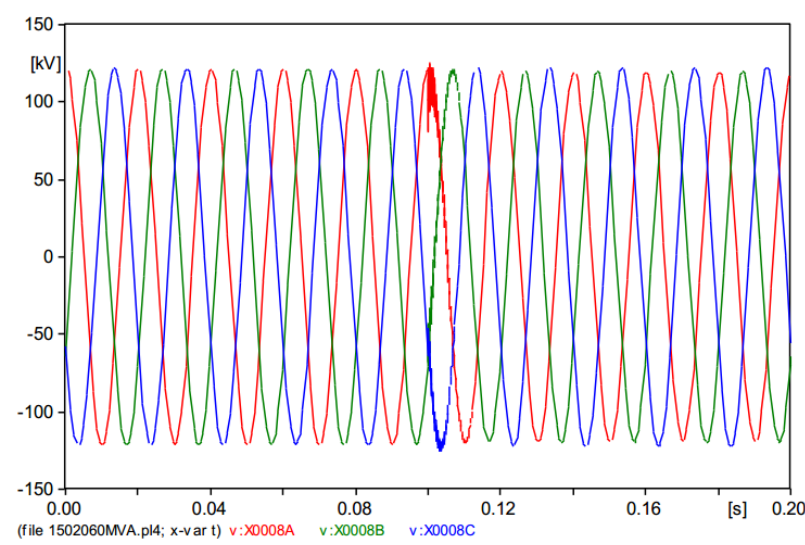

Fig. 13. Voltage waveform for phase to ground fault on secondary winding (Phase $\mathrm{R}=$ red, phase $\mathrm{S}=$ green and phase $\mathrm{T}=$ blue).

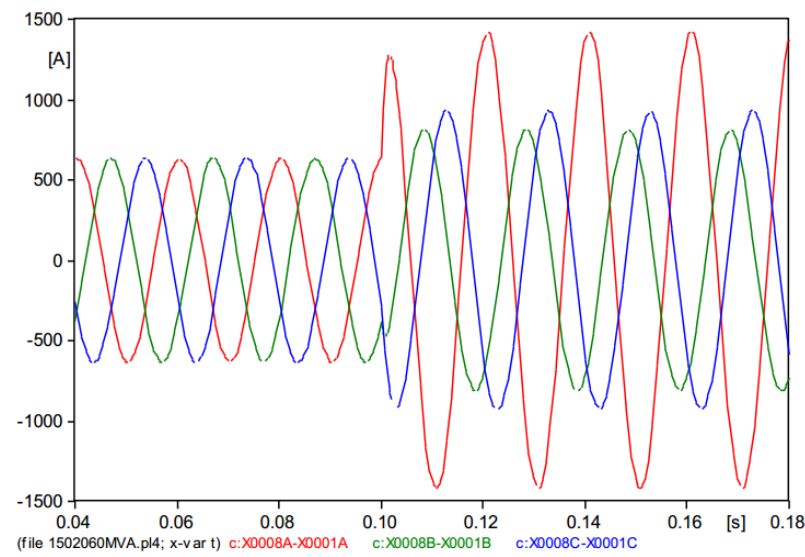

Fig. 14. Current waveform for phase to ground fault on secondary winding (Phase $\mathrm{R}=$ red, phase $\mathrm{S}=$ green and phase $\mathrm{T}=$ blue).

\section{Discussion}

Based on recorded fault data from 2016-2017, there were total 11 faults happened on the transmission line which connected to the transformer. High magnitude current generated by the fault gave mechanical stress to the winding of the transformer, hence the insulation between windings or between winding and tank would be compromised due to structural shift inside the transformer. The winding structure shift due to previous fault on the transformer was proven in SFRA test result as shown in Fig. 6 and Fig. 7. The compromised insulation inside the transformer might increase the possibility of phase to phase or even phase to ground short circuit. Since the simulation waveform result in Fig. 11 and Fig. 12 was identical to the DFR record, it's predicted that the possible cause of transformer failure was internal arcing on phase $\mathrm{R}$ of primary winding (150 $\mathrm{kV})$. According to the reference [10-14], internal arcing during fault could deform transformer tank which was similar to what happened in Fig. 1. Internal arcing vaporized the oil which increased the volume of flammable gasses inside the transformer.

The most damaged terminal in transformer bay marshalling kiosk was terminal 82 which connected to the wiring of phase R $150 \mathrm{kV}$ CT. The $150 \mathrm{kV}$ CT had 3 core and the third core was shorted using wire for future instalment of Bus Protection. Judging the arcing mark on CT terminal cover (Fig. 3), there's a possibility that the wire used for shorting the redundant third core was loose which accidently made the CT become open circuit. Open circuited CT created very high voltage difference between CT terminal to ground, resulting electrical arc on CT terminal and also on terminal 82 in marshalling kiosk. The burning on terminal 82 damaged the other terminal above it. Terminal 76-79 on marshalling kiosk was dedicated for phase $\mathrm{S}$ and phase $\mathrm{T} 150 \mathrm{kV}$ CT wiring, therefore the burning on terminal 82 also created open circuit in phase $\mathrm{S}$ and phase T $150 \mathrm{kV}$ CT. Arcing from $150 \mathrm{kV} \mathrm{CT}$ wiring to ground created voltage transfer which initiated short circuit between control cable in relay panel inside the control room to the ground. The arcing damaged whole CT wiring and rack which result in complete malfunction of transformer protection system. Malfunctioned protection system could not interrupt internal arcing fault on phase $\mathrm{R}$ winding, which created prolong arc resulting rapid increase of transformer oil pressure. Rapid increase of oil pressure might rupture the tank and shatter the lead bushing. Shattered bushing caused short circuit between high voltage lead with the tank which caught transformer on fire. The flame damaged the arrester next to the transformer as shown in Fig. 4.

\section{Conclusion}

The possible cause of transformer failure was internal arcing in phase $\mathrm{R}$ of primary winding which could not be interrupted by protection system. The malfunction of the protection system was caused by damaged $150 \mathrm{kV}$ CT wiring due to accidental open circuit on CT core.

\section{References}

1. IEEE Guide for Diagnostic Field Testing of Electric Power Apparatus - Part 1: Oil Filled Power Transformers, Regulators, and Reactors, in IEEE Std 62-1995, vol., no., pp.1-68 Dec. 1 (1995)

2. L. Yong, C. Yanjie, Q. Rui, J. Shengchang, L. Xianchen, Simulation study of influence of transformer bushing fault on frequency response curves, High Voltage Engineering, vol. 40, pp. 2406-2415 August (2014)

3. Abu-Siada, N. Hashemnia, S. Islam and M. A. S. Masoum, Understanding power transformer frequency response analysis signatures, in IEEE Electrical Insulation Magazine, vol. 29, no. 3, pp. 48-56 May-June (2013)

4. J. A. S. B. Jayasinghe, Z. d. Wang, P. N. Jarman and A. W. Darwin, Winding movement in power transformers: a comparison of FRA measurement connection methods, in IEEE Trans. on Dielectrics and Electrical Insulation, vol. 13, no. 6, pp. 13421349 (2006) 
5. IEC 60076-18 Ed. 1: Power Transformers - Part 18: Measurement of frequency response (2011)

6. IEEE Guide for the Application and Interpretation of Frequency Response Analysis for Oil-Immersed Transformers in IEEE Std C57.149-2012, vol., no., pp.1-72 March 8 (2013)

7. S. M. Islam, Detection of shorted turns and winding movements in large power transformers using frequency response analysis, 2000 IEEE Power Engineering Society Winter Meeting. Conference Proceedings (Cat. No.00CH37077), pp. 2233-2238 vol.3 (2000)

8. $\mathrm{Z}$ Wang, Artificial Intellegience Application in the Diagnosis of Power Transformers Incipient Faults, (Dissertation for $\mathrm{PhD}$ Degree in Virginia Polytechnic Institute and State University, 2000)

9. P. Henault, Detection of internal arcing faults in distribution transformers, 2011 IEEE PES $12^{\text {th }}$ International Conference on Transmission and Distribution Construction, Operation and Live-Line Maintenance (ESMO), Providence, RI, pp. 1-7 (2011)

10. IEEE Guide for Tank Rupture Mitigation of LiquidImmersed Power Transformers and Reactors in IEEE Std C57.156-2016, vol., no., pp.1-26 Dec. 21 (2016)

11. N. Abi-Samra, Power Transformer Tank Rupture and Mitigation-A Summary of Current State of Practice and Knowledge by the Task Force of IEEE Power Transformer Subcommittee, in IEEE Transactions on Power Delivery, vol. 24, no. 4, pp. 1959-1967 Oct. (2009)

12. J. B. Dastous, J. Lanteigne and M. Foata, Numerical Method for the Investigation of Fault Containment and Tank Rupture of PowerTransformers, in IEEE Transactions on Power Delivery, vol. 25, no. 3, pp. 1657-1665 July (2010).

13. G. Perigaud, S. Muller, G. de Bressy, R. Brady and P. Magnier, Contribution to the study of transformer tank rupture due to internal arcing development of a computer simulation tool, 2008 IEEE Power and Energy Society General Meeting Conversion and Delivery of Electrical Energy in the 21st Century, Pittsburgh, PA, pp. 1-8 (2008)

14. C. Yan, Simulation and analysis of power transformer internal arcing faults overpressure characteristics, 2014 International Conference on Power System Technology, Chengdu, pp. 685-690 (2014) 